\title{
Characterization of Dopamine Release in the Substantia Nigra by in vivo Microdialysis in Freely Moving Rats
}

\author{
George S. Robertson, Geert Damsma, and Hans C. Fibiger \\ Division of Neurological Sciences, Department of Psychiatry, University of British Columbia, Vancouver, British Columbia, \\ Canada V6T $1 Z 3$
}

\begin{abstract}
Dopamine (DA) is released not only from the terminals of the nigrostriatal projection, but also from the dendrites of these neurons, which arborize in the substantia nigra pars reticulata (SNR). Although striatal DA release has been extensively studied by in vivo microdialysis, dendritic DA release in the SNR has not been characterized by this technique. Extracellular DA was monitored simultaneously in the ipsilateral striatum and SNR. The nigral probe was implanted at a $50^{\circ}$ angle, permitting $2.5 \mathrm{~mm}$ of SNR to be dialyzed. Delivery of the tracer Fluoro-Gold into the striatal probe retrogradely labeled tyrosine hydroxylase-positive cell bodies and dendrites in the vicinity of the nigral probe. Hence, it could be demonstrated that dopaminergic neurons near the nigral probe projected to the vicinity of the striatal probe. Addition of $50 \mathrm{mM} \mathrm{KCl}$ to the SNR perfusion solution produced a 3.5 -fold increase in DA and a $50 \%$ reduction in dihydroxyphenylacetic acid (DOPAC) in the SNR; in contrast, this manipulation in the SNR caused DA release in the striatum to be decreased by $20 \%$, while striatal DOPAC was increased by $50 \%$. Local administration of nomifensine (10 $\mu \mathrm{M})$ in the SNR produced a sevenfold increase in SNR DA but had no effect on striatal DA. Systemic injection of d-amphetamine ( $2 \mathrm{mg} / \mathrm{kg}$, s.c.) elevated DA in the SNR and striatum five- to sevenfold, while DOPAC was decreased in both structures by at least $\mathbf{4 0} \%$. To determine the effect of tetrodotoxin (TTX), basal concentrations of DA in the SNR were first elevated threefold by including nomifensine $(1 \mu \mathrm{M})$ in the nigral perfusion solution. Under this condition, TTX (1 $\mu M)$ reduced DA release in both the SNR and striatum to below detectable limits. These data stand in contrast to previous push-pull cannula studies, which found that TTX increases ${ }^{3} \mathrm{H}-\mathrm{DA}$ release in the substantia nigra. The present results demonstrate that DA release in the SNR and striatum share similar characteristics and serve to illustrate the use of microdialysis for the simultaneous measurement of transmitter release from dendrites and terminals of the same population of dopaminergic neurons.
\end{abstract}

\footnotetext{
Received Nov. 15, 1990; revised Feb. 1, 1991 ; accepted Feb. 25, 1991.

We thank D. Wenkstern for her excellent technical assistance and Dr. K. Baimbridge for assistance with the photography. This work was supported by the Medical Research Council of Canada, Grant PG-23. G.S.R. was supported by a postdoctoral fellowship from the Medical Research Council of Canada.

Correspondence should be addressed to Dr. H. Christian Fibiger, Department of Neurological Science, 2255 Wesbrook Mall, University of British Columbia, Vancouver, BC, Canada V6T 1 Z3.

Copyright $(1991$ Society for Neuroscience $0270-6474 / 91 / 112209-08 \$ 03.00 / 0$
}

The discovery that dopamine (DA) is located not only in the terminals but also in perikarya and dendrites of nigrostriatal neurons led to the suggestion that DA may be released from dendrites in the substantia nigra (SN; Björklund and Lindvall, 1975). Subsequent immunohistochemical investigations have confirmed that the synthesizing enzymes for this catecholamine are also present in the dendrites of these neurons, some of which extend ventrally into the substantia nigra pars reticulata (SNR; Hökfelt et al., 1984; Jaeger et al., 1984). Further support for the suggestion that DA may be released from dendrites in the SN has come from studies demonstrating that intranigral delivery of amphetamine decreases the firing of nigrostriatal neurons, while local application of haloperidol increases the activity of these neurons (Groves et al., 1975; Aghajanian and Bunney, 1977). Since the original description of DA-containing dendrites in the SNR, dendritic release of ${ }^{3} \mathrm{H}-\mathrm{DA}$ has been demonstrated using nigral slices (Geffen et al., 1976), and in vivo by push-pull superfusion methodologies (for review, see Cheramy et al., 1981). In the latter studies, local application of $\mathrm{KCl}(30 \mathrm{~mm})$, amphetamine $(1 \mu \mathrm{M})$, and benztropine $(1 \mu \mathrm{M})$ were found to increase ${ }^{3} \mathrm{H}-\mathrm{DA}$ release in the SN (Nieoullon et al., 1977a). However, in contrast to DA release in the striatum, blockade of fast sodium channels with tetrodotoxin (TTX) increased, rather than decreased ${ }^{3} \mathrm{H}-\mathrm{DA}$ release in the $\mathrm{SN}$ (Nieoullon et al., 1977a). As a result, it has been suggested that a TTX-resistant, voltagedependent calcium conductance may mediate dendritic DA release in the SN (Nedergaard et al., 1989).

Several lines of evidence indicate that DA release in the $\mathrm{SN}$ influences basal ganglia neurotransmission by activating either $D_{1}$ receptors on the terminals of striatonigral neurons or $D_{2}$ receptors located on the cell bodies and dendrites of dopaminergic neurons (Aghajanian and Bunney, 1977; Gale et al., 1977; Reisine et al., 1979; Kozlowski et al., 1980; Cheramy et al., 1981; Kelly et al., 1984; Robertson and Robertson, 1987, 1989). Activation of nigral $\mathrm{D}_{2}$ receptors by dendritically released DA may serve an autoinhibitory role and thereby decrease striatal DA release (Cheramy et al., 1981). The reduction in dopaminergic cell firing (Aghajanian and Bunney, 1977) and ${ }^{3} \mathrm{H}-\mathrm{DA}$ release in the striatum (Nieoullon et al., 1977b) after $D_{2}$ receptor activation in the SN and the reversal of these inhibitory actions by neuroleptics are consistent with this hypothesis. On the other hand, DA and the selective $D_{1}$ agonist SKF 38393 have been demonstrated to increase ${ }^{3} \mathrm{H}-\mathrm{GABA}$ release from nigral slices (Reubi et al., 1977; Starr, 1987). This result suggests that, in vivo, dendritically released DA may increase the release of GABA in the SNR by activating $D_{1}$ receptors located on terminals of striatonigral neurons (Reubi et al., 1977; Kozlowski et al., 1980; 
Gauchy et al., 1987; Robertson and Robertson, 1987; Starr, 1987; Starr and Starr, 1989).

Despite the large number of neurochemical, neuropharmacological, elecrophysiological and behavioral studies suggesting that DA is released from the dendrites of nigrostriatal neurons, release of endogenous DA in the $\mathrm{SN}$ has not been demonstrated. Consequently, we attempted to characterize the endogenous release of DA in the SNR of freely moving animals by in vivo microdialysis. In order to determine the effect of manipulating dendritic DA release on striatal DA output and metabolism, extracellular DA and metabolites were monitored simultancously in the ipsilateral SNR and striatum. In addition, the effect of local application of $\mathrm{KCl}$, nomifensine, and TTX in the SNR, as well as systemically administered $d$-amphetamine on DA release, was evaluated in the ipsilateral SNR and striatum of freely moving rats.

\section{Materials and Methods}

Microdialysis probe construction. Concentric microdialysis probes were constructed using a design similar to that of Church and Justice (1987) and Robinson and Whishaw (1988). Construction of the probe commenced with the preparation of a 23-gauge stainless-steel main shaft 5$6 \mathrm{~mm}$ in length, and two lengths of 23-gauge stainless-steel tubing, each approximately $8 \mathrm{~mm}$ with a bevel at one end, which housed and protected fused silica capillary inlet and outlet tubing (i.d., $75 \mu \mathrm{m}$; o.d., $150 \mu \mathrm{m}$; Polymicro Technologies, Phoenix, AZ). The dialysis membrane, a copolymer of polyacrylonitrile and sodium methallyl sulfonate (Hospal-gambro Inc.; 40,000 molecular cutoff; i.d., $0.240 \mathrm{~mm}$; dry) was glued to the main shaft with 2-ton epoxy (Devcon, Chicago, IL). One of the lengths of fused silica capillary tubing was inserted through the main shaft and dialysis membrane, terminating $0.3 \mathrm{~mm}$ from the end of the membrane. This length of silica tubing served as the probe inlet. A second 23-gauge cannula containing a shorter length of silica tubing was inserted into the main shaft of the probe and served as the outlet. The three-way junction between the main shaft, inlet, and outlet was secured with heat-shrink tubing (Small Parts Inc., Miami, FL) and 2-ton epoxy. The membrane was then capped with a small quantity of 2-ton epoxy and was completely covered with glue except for the exposed length. The nigral probes had effective dialysis-surface distances of 2.5 $\mathrm{mm}$. In order to sample the extracellular concentration of DA and metabolites from both the dorsal and the ventral aspects of the striatum, the striatal probes had a $4.5-\mathrm{mm}$ exposed surface. Probes were rinsed with alcohol (80\%) for 12-24 hr and then for at least $2 \mathrm{hr}$ with sterile water prior to implantation. In vitro recoveries of DA, 3,4-dihydroxyphenylacetic acid (DOPAC), homovanillic acid (HVA), and 5-hydroxyindolacetic acid (5-HIAA) for the nigral probes were $6.8 \pm 0.3 \%, 4.8$ $\pm 0.4 \%, 4.7 \pm 0.4 \%$, and $4.7 \pm 0.4 \%$, respectively $(n=4)$. In vitro recoveries of DA, DOPAC, HVA, and 5-HIAA for the striatal probes were $13.1 \pm 0.8 \%, 9.1 \pm 0.6 \%, 9.7 \pm 1.3 \%$, and $9.8 \pm 1.2 \%$, respectively $(n=4)$.

Surgery. The dialysis probes were implanted in the medial aspect of the SNR and ipsilateral striatum of 25 male Wistar rats $(280-300 \mathrm{gm})$ under pentobarbital anesthesia $(60 \mathrm{mg} / \mathrm{kg}$, i.p.). To perfuse most of the medial-lateral (ML) extent of the SNR, the nigral probe was implanted at an angle that was $50^{\circ}$ to the dorsal-ventral (DV) plane. In brief, approximately $15 \mathrm{~min}$ after the onset of anesthesia, subjects were placed in a Kopf stereotaxic frame with the nose bar fixed $-4.2 \mathrm{~mm}$ below 0 . The positioning arm of the stereotaxic frame was secured at a $50^{\circ}$ angle (arm set to $-5.0 \mathrm{~mm}$ ) to the dorsal-ventral plane at interaural 0 . The nigral probe was gently lowered into the SNR through a small burr hole in the temporal skull plate [anterior-posterior (AP) 3.0, ML 0.35, DV 2.2 from interaural 0 according to the atlas of Paxinos and Watson, 1986]. The nigral probe was then secured in position with dental cement to four anchoring screws on the top of the skull. The striatal probe was lowered vertically into the striatum and was also secured with dental cement to the four anchoring screws on the top of the skull (AP 1.0, ML -2.8 , DV -7.2 from bregma according to Paxinos and Watson, 1986). Animals were housed individually in Perspex cages $(35 \times 35 \times$ $40 \mathrm{~cm}$ ) with free access to food and water. Dialysis commenced $2 \mathrm{~d}$ after surgery.

Microdialysis. Microdialysis and on-line analysis were performed according to Damsma et al. (1990). Briefly, the inlet cannula of the probe was connected to a perfusion pump (Carnegie Medicin) while the outlet was connected to the sample loop $(100 \mu 1)$ of an electrically actuated sample injector by polyethylene tubing (i.d., $0.28 \mathrm{~mm}$; length, $80 \mathrm{~cm}$ ). The injector was set in the load for position for $20 \mathrm{~min}$ and was subsequently switched to the inject position for $24 \mathrm{sec}$, after which time the cycle was repeated. These alternating modes of sample valve collection were controlled by an adjustable timer (Valco). The dialysis fibers were perfused with a $1.5 \mathrm{mM}$ sodium phosphate-buffered solution containing $147 \mathrm{mM} \mathrm{NaCl}, 3 \mathrm{mM} \mathrm{KCl}, 1 \mathrm{mM} \mathrm{MgCl}$, and $1.3 \mathrm{mM} \mathrm{CaCl}_{2}$, (pH 7.3) at $5 \mu \mathrm{l} / \mathrm{min}$.

Biochemical assay. Dopamine, DOPAC, HVA, and 5-HIAA were quantified by HPLC in conjunction with electrochemical detection (Damsma et al., 1990). The mobile phase was delivered by a dual-piston pump (Biorad) at $1.5 \mathrm{ml} / \mathrm{min}$ and consisted of $0.1 \mathrm{M}$ acetic acid adjusted to $\mathrm{pH} 4.1$ with solid sodium acetate, $0.5 \mathrm{~mm}$ octanesulfonic acid (Kodak), $0.01 \mathrm{mM} \mathrm{Na}{ }_{2} \mathrm{EDTA}$, and $150 \mathrm{ml}$ of methanol/liter. A precolumn $(50 \times 3 \mathrm{~mm}$; Nucleosil $5 \mathrm{Cl}$ ) $)$ was placed between the pump and injector. Dopamine and metabolites were separated by reverse-phase liquid chromatography (column: $150 \times 4.8 \mathrm{~mm}$, Nucleosil 5C18). Electrochemical detection of nigral DA and metabolites was achieved by setting the glassy carbon working electrode at $+700 \mathrm{mV}$ against the $\mathrm{Ag} / \mathrm{AgCl}$ reference electrode of the electrochemical detector (LC4B, BAS). Detection of striatal DA and metabolites was performed by the sequential oxidation and reduction of samples by a coulometric detection system (coulometric electrode, $+0.4 \mathrm{~V}$; amperometric electrode, $-0.2 \mathrm{~V}$; ESA, cell 5011). Metabolites were detected by the coulometric cell, while DA was quantified with the subsequent amperometric electrode. The chromatograms were recorded on a dual-pen chart recorder (Kipp). The detection limit of the BAS system was about $4 \mathrm{fmol} /$ injection for DA, DOPAC, and 5-HIAA and $20 \mathrm{fmol} /$ injection for HVA. The detection limit of the ESA system was about $6 \mathrm{fmol} /$ injection for DA, DOPAC, and 5-HIAA and $20 \mathrm{fmol} /$ injection for HVA.

Experimental protocol. Microdialysis and analysis of DA and metabolites were performed simultaneously in the striatum and SNR. The effect of perfusing the nigral probe with $\mathrm{KCl}(50 \mathrm{mM})$ for $40 \mathrm{~min}$ and nomifensine $(10 \mu \mathrm{M})$ for $20 \mathrm{~min}$ on nigral and striatal DA and metabolites was evaluated $(n=6)$. Because the concentration of DA in the nigral dialysate was near the limit of detection, DA in the SNR was first elevated 3.5-fold by perfusion with nomifensine $(1 \mu \mathrm{M})$ for $80 \mathrm{~min}$; TTX $(1 \mu \mathrm{M})$ was then also included in the nigral perfusion solution for $80 \mathrm{~min}(n=5)$. The effect of $d$-amphetamine sulphate $(2 \mathrm{mg} / \mathrm{kg}$, s.c.) on the output of DA and metabolites from the SNR $(n=7)$ and striatum $(n=5$; striatal probes of two animals plugged) was evaluated in a second group of rats that contained two animals from the first group. Basal DA and metabolite concentrations in the striatum and SNR were stable and had returned to pretreatment values for at least $60 \mathrm{~min}$ before beginning each new experimental manipulation $(\mathrm{KCl}, \mathrm{TTX}$, etc.). In addition, the order of drug treatments was varied between animals to control for potential order effects.

Histology. The striatal probes of three rats were filled with a saline $(0.9 \%)$ solution containing $4 \%$ Fluoro-Gold (FG), and $12 \mathrm{hr}$ later the probes were flushed with saline. One week later, these animals were given an overdose of pentobarbital and perfused transcardially with 100 $\mathrm{ml}$ of saline followed by $200 \mathrm{ml}$ of $0.1 \mathrm{M}$ phosphate-buffered saline (PBS) containing 4\% paraformaldehyde (PFA). The brains were removed, postfixed in $4 \%$ PFA for $12 \mathrm{hr}$, transferred to $0.02 \mathrm{M}$ PBS, and stored at $4^{\circ} \mathrm{C}$. Sections $35 \mu \mathrm{m}$ thick were cut at room temperature with a vibrotome (Oxford) through the striatal and nigral implantation sites. Nigral sections were washed three times for $20 \mathrm{~min}$ with $0.02 \mathrm{~m}$ PBS and incubated in a cocktail containing $0.3 \%$ Triton $X-150,0.02 \%$ azide, and rabbit anti-tyrosine hydroxylase primary antibody (Eugene Tech) suspended in $0.02 \mathrm{M}$ PBS for $48 \mathrm{hr}$. The sections were then washed three times with $0.02 \mathrm{M}$ PBS and incubated in a cocktail containing $0.3 \%$ Triton $\mathrm{X}-150,0.02 \%$ azide, and Texas Red-labeled goat antirabbit antibody (Jackson Laboratories). After three washes with $0.02 \mathrm{M}$ PBS, the sections were mounted and coverslipped with immersion oil (Zeiss). The sections were observed under a fluorescent Zeiss microscope using green light $(530-560 \mathrm{~nm})$ to visualize Texas Red-fluorescent neurons and ultraviolet light $(340-380 \mathrm{~nm})$ to visualize FG-labeled cell bodies. The brains of the remaining animals were removed and sliced at $40 \mu \mathrm{m}$ on a freezing microtome to examine the position of the striatal and nigral membranes microscopically.

Statistics. The average of the last three or four (less than $10 \%$ variation) stable samples before treatment was considered as the control and defined as $100 \%$. Data were analyzed using a one-way analysis of variance (ANOVA) with repeated measures. Individual comparisons were performed using Student's $t$ test. 
Table 1. Basal DA and metabolite values (mean \pm SEM) in dialysate from the ipsilateral SNR and striatum

\begin{tabular}{lcc} 
& $\begin{array}{l}\text { SNR } \\
(\mathrm{fmol} / \mathrm{min} ; n=11)\end{array}$ & $\begin{array}{l}\text { Striatum } \\
(\mathrm{fmol} / \mathrm{min} ; n=9)\end{array}$ \\
\hline DA & $0.61 \pm 0.12$ & $5.13 \pm 0.58$ \\
DOPAC & $83.2 \pm 13.8$ & $790.4 \pm 74.2$ \\
HVA & $81.3 \pm 11.7$ & $517.3 \pm 43.2$ \\
5-HIAA & $392.2 \pm 32.0$ & $350.0 \pm 43.5$
\end{tabular}

\section{Results}

\section{Histology}

Basal DA in nigral dialysate was detectable for the duration of the experiment in 11 animals. Histological examination of the SN of these animals revealed that the implantation site corresponded to a region $0.2-0.5 \mathrm{~mm}$ from the ventral surface of substantia nigra pars compacta (SNC) cell bodies in the medial aspect of the SNR (Fig. $1 A, B$ ). Basal DA was undetectable if the nigral probe was implanted outside this region $(n=14)$. Delivery of FG into the striatal probe retrogradely labeled cell bodies and dendrites in the SNC (Fig. 1C). FG-labeled cell bodies and dendrites in the SNC were tyrosine hydroxylase positive, indicating that dopaminergic neurons near the nigral probe projected to the vicinity of the striatal probe (Fig. $1 B, C$ ). Dopaminergic dendrites were often observed to surround the nigral probe (Fig. $1 B, C$ ). Striatal probes were located in the medial aspect of the striatum in all of the animals (results not shown).

\section{Comparison of basal DA and metabolite output in the SNR and striatum}

Basal DA, DOPAC, HVA, and 5-HIAA output values in dialysate from the ipsilateral SNR $(n=11)$ and striatum $(n=9)$ are presented in Table 1. DA, DOPAC, and HVA in the SNR were approximately $10 \%$ of the corresponding striatal values, while 5-HIAA was comparable in the two regions (Table 1). However, the exposed length of the nigral probe was approximately $50 \%$ that of the striatal probe, suggesting that the extracellular concentration of 5-HIAA in the SNR is approximately double that in striatum. The HVA:DOPAC ratio in the SNR was significantly higher than that in the striatum (Table 2).

\section{Effect of perfusing the SNR with $\mathrm{KCl}(50 \mathrm{~mm})$ and nomifensine $(10 \mu \mathrm{M})$ on DA and metabolite output in the SNR and striatum}

Perfusion of the SNR for $40 \mathrm{~min}$ with $\mathrm{KCl}(50 \mathrm{~mm})$ increased DA release in the SNR by more than threefold $(n=6 ; p<0.01$; Fig. $2 A$ ). In contrast, DA was slightly, but significantly, reduced in the striatal dialysate samples during perfusion of the SNR with this high concentration of potassium $(n=6 ; p<0.05$; Fig. $2 A$ ). The high potassium decreased DOPAC, HVA, and 5-HIAA in the nigral dialysate $(p<0.01$; Fig. $2 B$ ), whereas DOPAC and HVA were elevated in the striatum by this treatment $(p<0.05$; Fig. $2 C$ ). Inclusion of the DA uptake inhibitor nomifensine (10 $\mu \mathrm{M})$ in the nigral perfusion solution for $20 \mathrm{~min}$ elevated nigral concentrations of DA about sevenfold ( $p<0.01$; Fig. 3A). Nomifensine did not, however, alter the DA metabolites in the SNR (Fig. 3B). DA and metabolite concentrations in the striatum were not changed during perfusion of the SNR with nomifensine (Fig. 3C).
Table 2. DA and metabolite ratios (mean \pm SEM) for basal DA, DOPAC, and HVA concentrations in dialysate from the ipsilateral SNR and striatum

\begin{tabular}{lll} 
& SNR $(n=11)$ & Striatum $(n=9)$ \\
\hline DOPAC:DA & $158.9 \pm 23.5$ & $168.0 \pm 22.4$ \\
HVA:DA & $157.6 \pm 22.5$ & $106.9 \pm 8.96$ \\
HVA:DOPAC* & $1.029 \pm 0.052$ & $0.672 \pm 0.048$
\end{tabular}

Statistical comparisons between DA and metabolite ratios for the SNR and striatum were performed using a two-tailed $t$ test. ${ }^{*}, p<0.001$.

Effect of perfusing the SNR with nomifensine $(1 \mu \mathrm{M})$ and TTX $(1 \mu \mathrm{M})$ on DA and metabolite output from the SNR and striatum

In this experiment, perfusion of the SNR with nomifensine (1 $\mu \mathrm{M})$ elevated nigral DA by over threefold $(n=5 ; p<0.01$; Fig. $4 A$ ) but did not alter metabolite concentrations in the SNR dialysate (Fig. $4 B$ ). Striatal DA and metabolites were again not altered by elevation of nigral DA with nomifensine (Fig. $4 A, C$ ). Inclusion of TTX $(1 \mu \mathrm{M})$ to the nigral perfusion solution resulted in a rapid and near complete block of DA release in both the SNR and the striatum (Fig. $4 A ; p<0.01$ ). In the SNR, HVA, but not DOPAC, was increased during the combined nigral perfusion of nomifensine and TTX (Fig. $4 B ; p<0.01$ ). DOPAC and HVA concentrations in the striatum were increased dramatically by inclusion of TTX $(1 \mu \mathrm{M})$ to the nigral perfusion solution (Fig. $4 C ; p<0.01$ ).

\section{Effect of systemically administered $\mathrm{d}$-amphetamine on $D A$ and metabolite output from the SNR and striatum}

$d$-amphetamine ( $2 \mathrm{mg} / \mathrm{kg}$, s.c.) produced a five- to sevenfold increase in DA release in both the striatum $(n-5)$ and SNR $(n=7 ; p<0.01 ;$ Fig. $5 A)$. The time courses of the amphetamineinduced DA release in the striatum and SNR were not statistically different $(p>0.5 ;$ Fig. $5 A)$. $d$-amphetamine decreased DOPAC in the SNR $(p<0.01$; Fig. $5 B)$, while both DOPAC and HVA were reduced in the striatum $(p<0.01$; Fig. 5C). $d$-amphetamine slowly increased 5-HIAA concentrations in the nigral and striatal dialysates ( $p<0.05$; Fig. 5B,C).

\section{Discussion}

In agreement with previous studies, perfusion of the SNR with a high concentration of potassium $(50 \mathrm{~mm})$ or a DA uptake blocker (nomifensine) increased endogenous concentrations of extracellular DA in the SNR (Nieoullon et al., 1977a; Cheramy et al., 1981). However, the absence of detectable DA in both the nigral and striatal dialysates after perfusion of the SNR with TTX $(1 \mu \mathrm{M})$ is a notable discrepancy with the results of pushpull superfusion studies, which have reported that TTX increases ${ }^{3} \mathrm{H}$-DA release in the SNR (Nieoullon et al., 1977a; Cheramy et al., 1981). Several differences between the push-pull and microdialysis methodologies may account for this discrepancy. First, most push-pull studies have measured the release of newly synthesized ${ }^{3} \mathrm{H}-\mathrm{DA}$ in the SNR. It is possible that dendritic release of newly synthesized ${ }^{3} \mathrm{H}-\mathrm{DA}$, unlike endogenous DA release, is not dependent on the propagation of action potentials by voltage-sensitive sodium channels. Second, push-pull studies are usually performed within hours after implantation of the probe; in the present study, microdialysis was performed $48 \mathrm{hr}$ after probe implantation, at which time DA release has been shown to be calcium dependent and TTX sensitive (Nomikos 


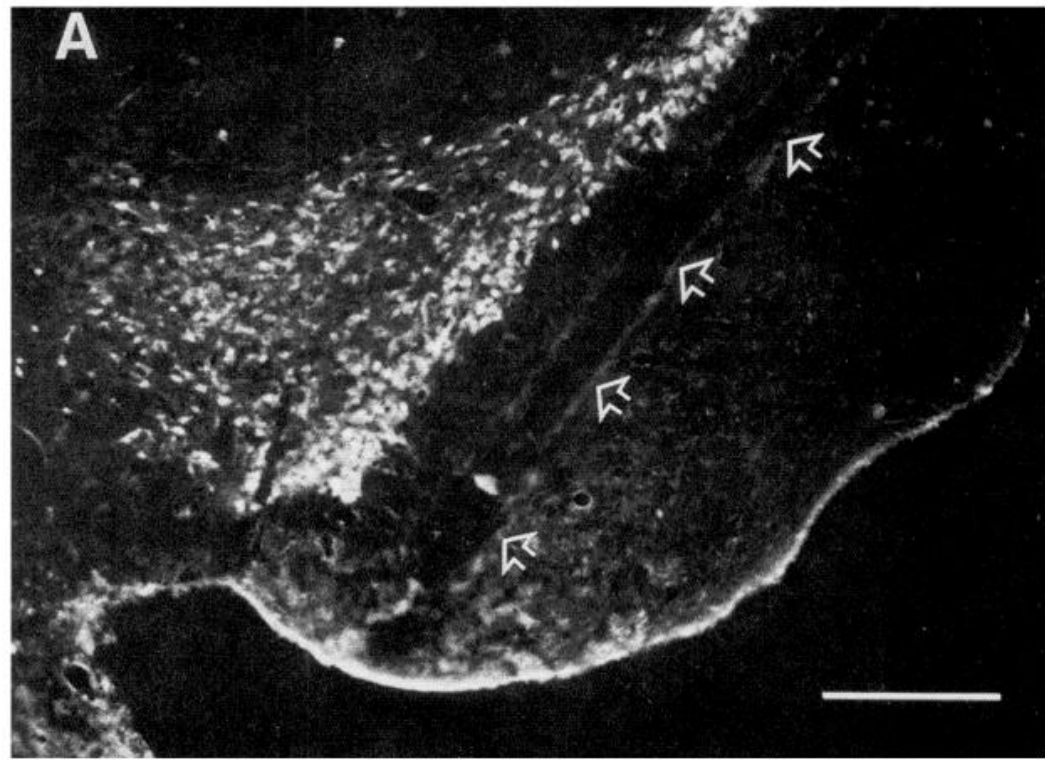

Figure 1. Photomicrographs of nigrostriatal neurons in the vicinity of a dialysis probe placed in the SNR. $A$, The tract produced by the dialysis membrane (arrows) can be observed to span the ML extent of tyrosine hydroxylase-immunoreactive cell bodies in the SNC. The dialysis probe is approximately $0.2 \mathrm{~mm}$ ventral to the dopaminergic perikarya comprising the SNC. Scale bar, $0.5 \mathrm{~mm}$. B, High-power photomicrograph of tyrosine hydroxylaseimmunoreactive neurons in the vicinity of the dialysis membrane. Stained dendrites (open arrows) can be observed to extend ventrally from the labeled cell bodies in the SNC so as to be in close proximity to the dialysis probe tract. $C, \mathrm{SNC}$ neurons retrogradely labeled by filling the striatal dialysis probe with FG. Some FG-labeled neurons also contain tyrosine hydroxylase ( $B$ and $C$, solid arrows). Some FG-labeled dendrites can be seen to extend ventrally towards the dialysis probe tract (open arrows). Scale bar for $B$ and $C, 0.25$ $\mathrm{mm}$.
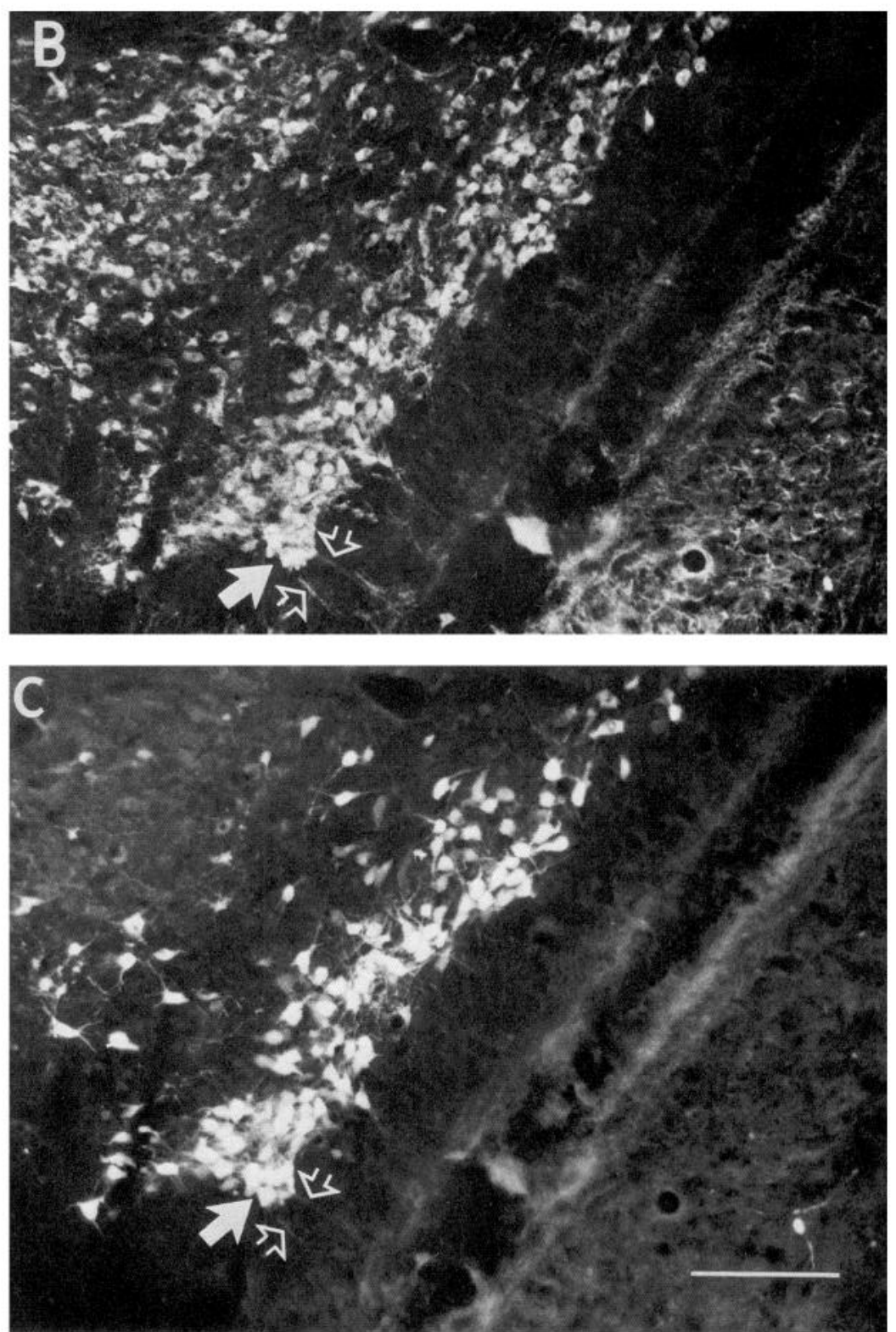

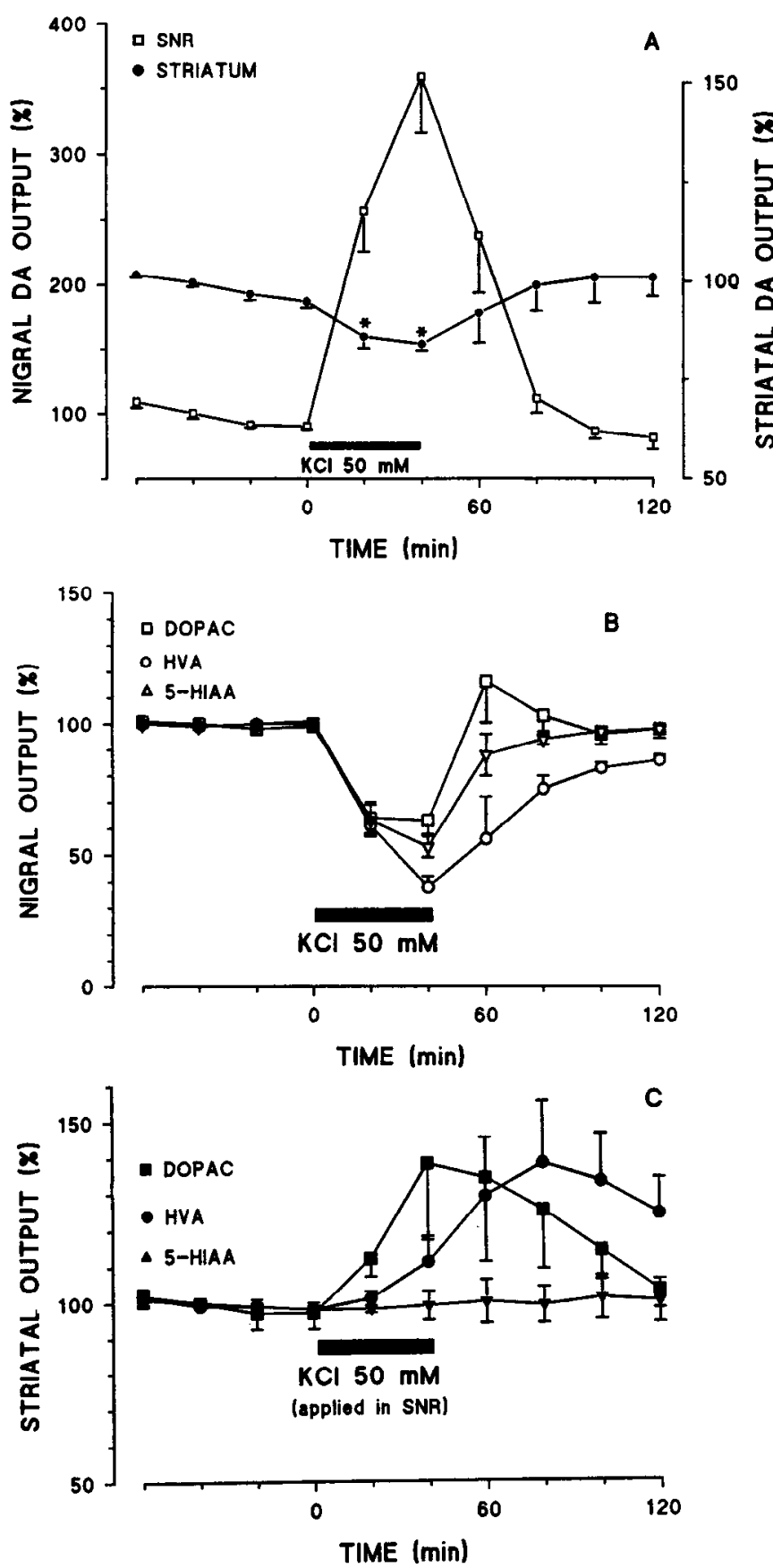

Figure 2. The effect of perfusing the SNR with a high concentration of $\mathrm{KCl}(50 \mathrm{~mm})$ on DA and metabolite output in the ipsilateral SNR and striatum. Each data point is the mean \pm SEM for six animals. $A$, Perfusion with $\mathrm{KCl}(50 \mathrm{~mm})$ for $40 \mathrm{~min}$ significantly increased DA release in the SNR $(p<0.01)$, while DA release was simultaneously decreased in the striatum $\left(^{*}, p<0.05\right) . B$ and $C$, DA metabolites in the SNR were reduced by high potassium $(p<0.01)$, whereas this treatment increased DOPAC and HVA output in the striatum $(p<0.05)$.

et al., 1990). At intervals less than $24 \mathrm{hr}$ after probe implantation, DA release is only partly calcium- and TTX-sensitive and may represent damage related efflux (Westerink and De Vries, 1988). Third, in push-pull studies, the rapid movement of fluid during perfusion may damage tissue surrounding the probe. In contrast, tissue around the microdialysis membrane is not subjected to the potentially damaging effects of superfusion. In summary, the 2 -d recovery period after probe implan-
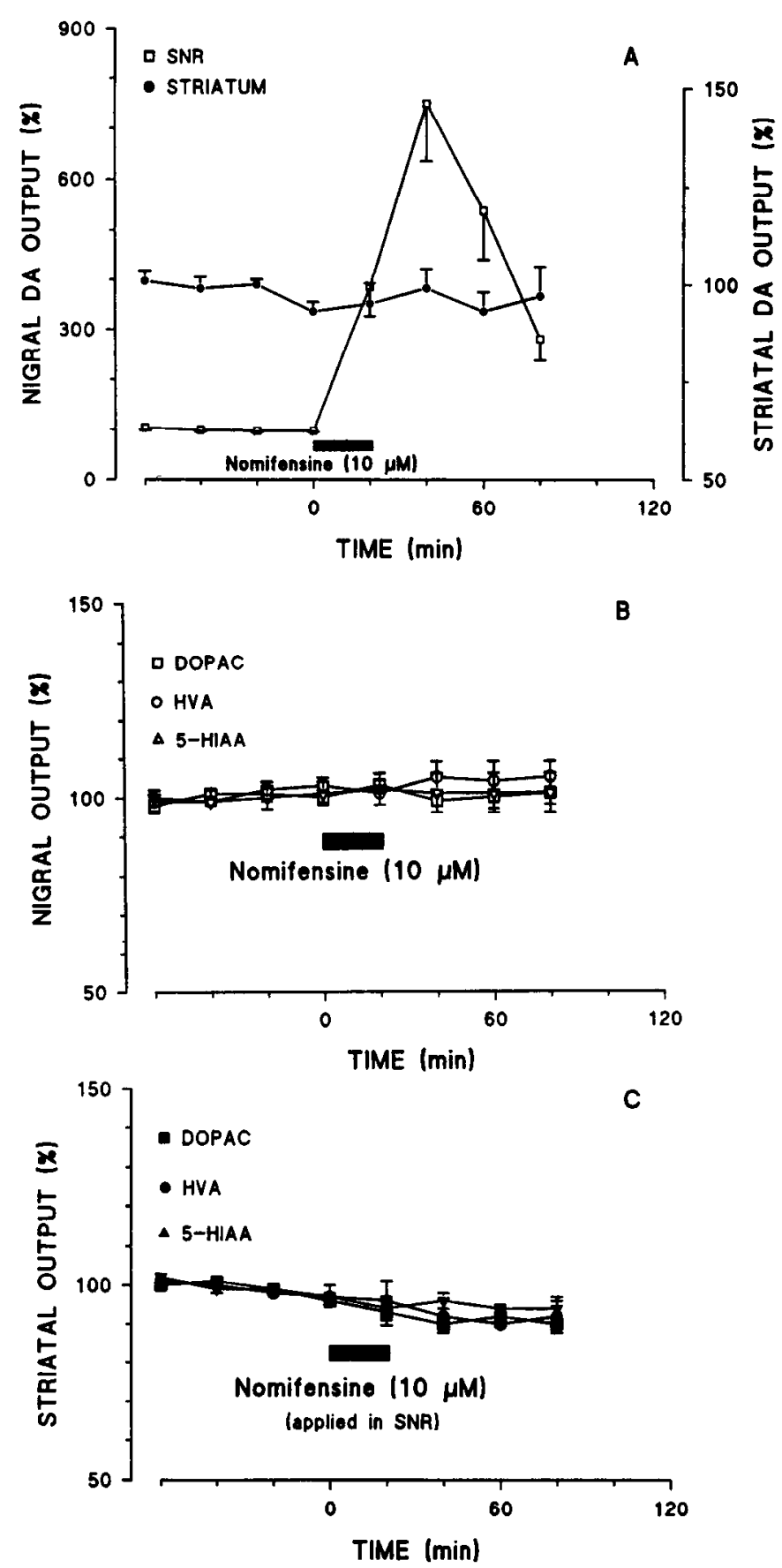

Figure 3. The effect of local application of nomifensine $(10 \mu \mathrm{M})$ to the SNR on DA and metabolite output in the SNR and striatum. Each data point is the mean \pm SEM for six animals. $A$, Nomifensine increased DA output in the SNR $(p<0.01)$ but was without significant effect in the striatum. $B$ and $C$, Metabolite output in the SNR and striatum was not altered by perfusion of the SNR with nomifensine.

tation and the less disruptive nature of microdialysis may account for the complete TTX sensitivity of DA release measured in the SNR by this technique. It should also be noted that the large reductions in extracellular striatal DA concentrations after nigral application of TTX suggests that striatal DA release is highly dependent on the propagation of action potentials generated in the $\mathrm{SN}$.

The SN receives a significant input from 5-HT-containing neurons of the raphe nuclei (Dray et al., 1976; Fibiger and Miller, 

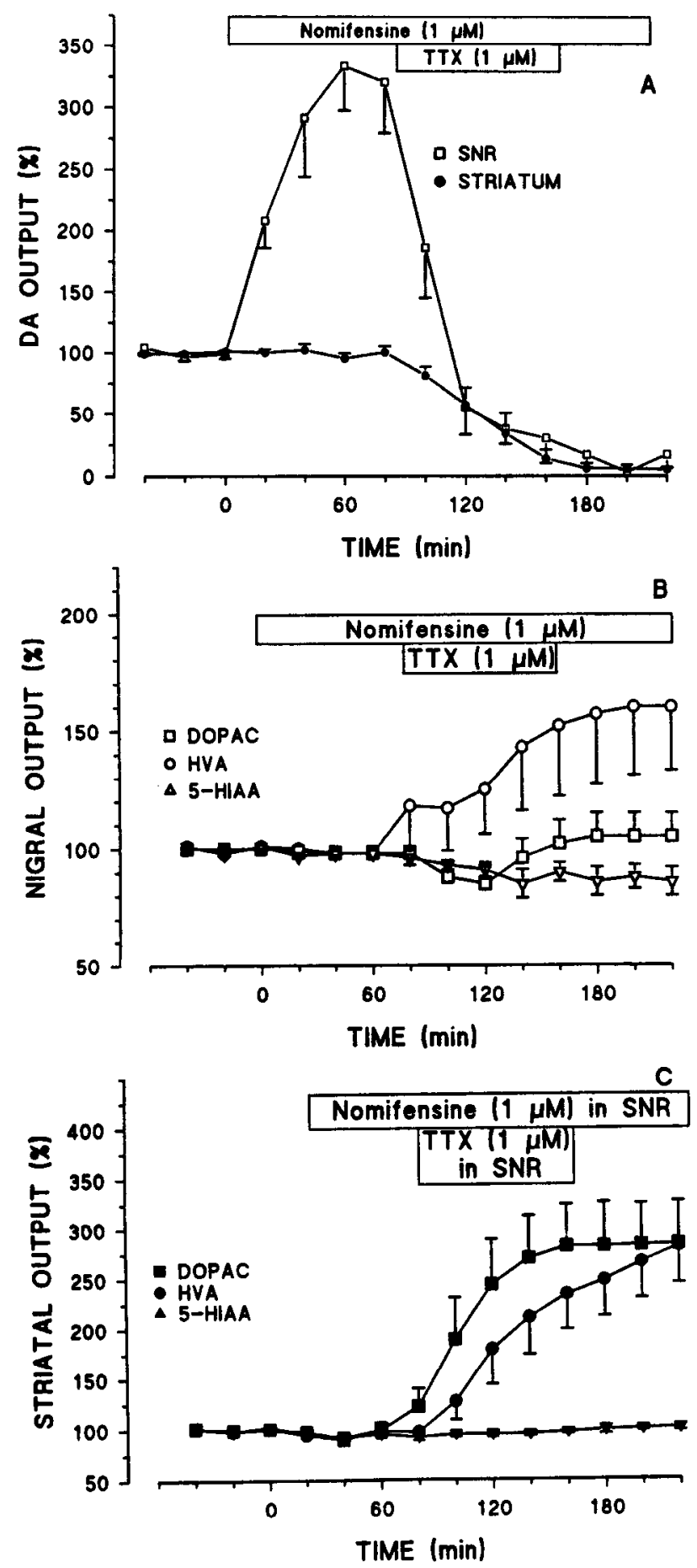

Figure 4. The effect of local perfusion of the SNR with nomifensine $(1 \mu \mathrm{M})$ and TTX $(1 \mu \mathrm{M})$ on DA and metabolite output in the SNR and striatum. Each data point is the mean \pm SEM for five animals. $A$, Nomifensine significantly elevated DA in the SNR $(p<0.01)$ but did not alter striatal DA output. Inclusion of TTX $(1 \mu \mathrm{M})$ in the nigral perfusion solution produced a rapid decline in DA output in the SNR $(p<0.01)$ and striatum $(p<0.01)$ to levels below the detection limit. $B$ and $C$, TTX increased HVA output in the SNR $(p<0.01)$ and increased DOPAC and HVA output in the striatum $(p<0.01)$.

1977). In vitro studies suggest that serotonergic terminals in the SN can take up and release ${ }^{3} \mathrm{H}-\mathrm{DA}$ (Kelly et al., 1985). It is therefore possible that a small portion of the DA recovered from the SNR may have originated from non-dopaminergic neurons.
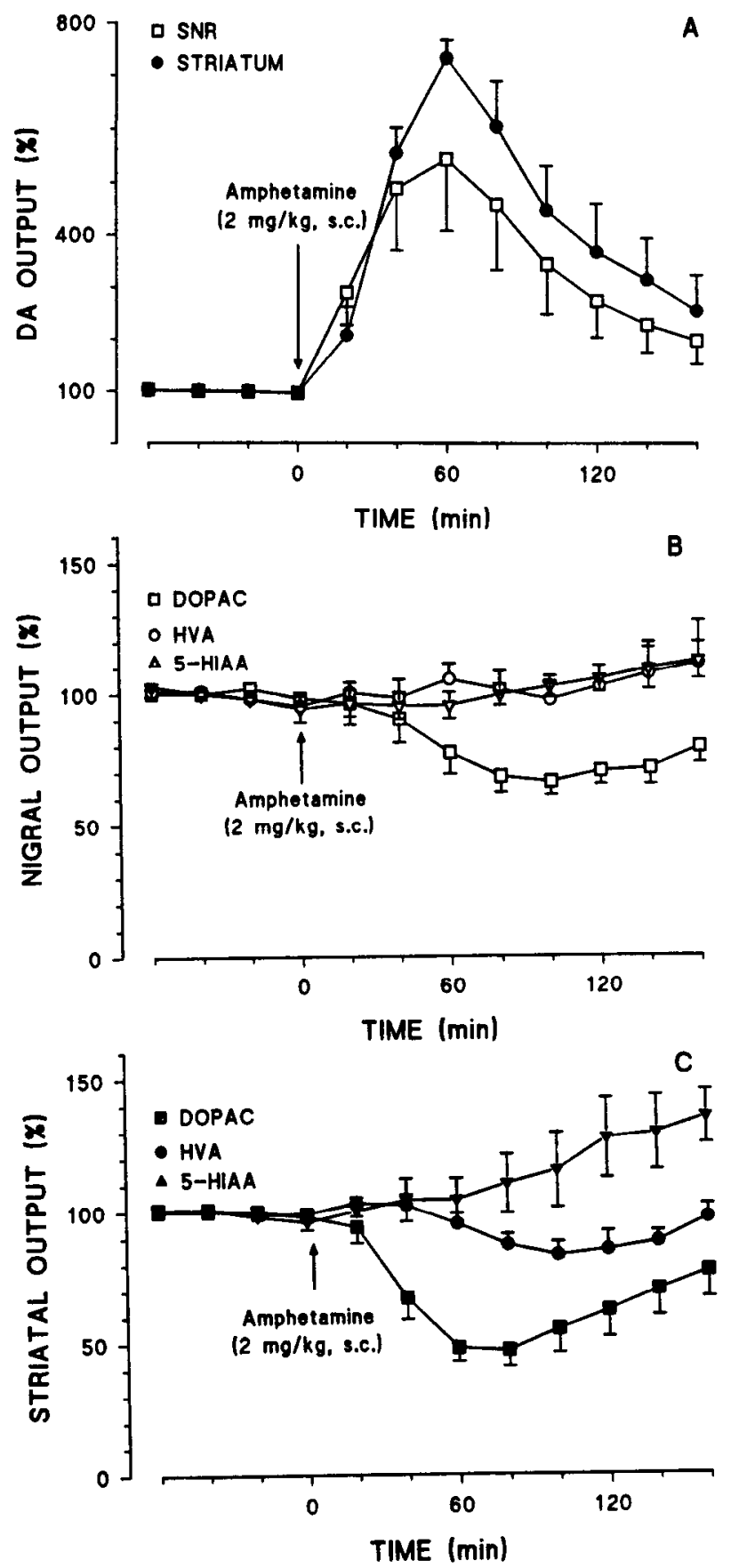

Figure 5. Effect of $d$-amphetamine $(2 \mathrm{mg} / \mathrm{kg}$, s.c.) on DA and metabolite output in the SNR and striatum. Each data point is the mean \pm SEM for five to seven animals. $A, d$-amphetamine increased DA output in the SNR $(p<0.01)$ and striatum $(p<0.01)$, and these increases were of similar magnitude and duration. $B$ and $C$, DOPAC was significantly reduced in the SNR by amphetamine $(p<0.01)$, whereas both DOPAC and HVA were significantly reduced in the striatum $(p<0.01)$. $d$-amphetamine significantly increased extracellular concentrations of 5-HIAA in the SNR and striatum $(p<0.05)$.

Activation of $\mathrm{D}_{2}$ receptors located on dopaminergic cell bodies and dendrites in the SN decreases the electrophysiological activity of SNC neurons (Aghajanian and Bunney, 1977; Nieoullon et al., 1977b). Hence, the ability of apomorphine to decrease and haloperidol to increase the loss of DA after administration of the tyrosine hydroxylase inhibitor $\alpha$-methylparatyrosine is thought to be mediated by inhibitory presynaptic receptors that 
regulate DA synthesis and release (Anden et al., 1967, 1971). Surprisingly, a sevenfold elevation in extracellular concentrations of nigral DA by nomifensine $(10 \mu \mathrm{M})$ failed to influence extracellular concentrations of DA, DOPAC, and HVA in the striatum. This result may indicate that an insufficient number of $\mathrm{D}_{2}$ autoreceptors in the SN were activated by a 20-min application of nomifensine to decrease DA release in the ipsilateral striatum. Alternatively, it may be that basal concentrations in the $\mathrm{SN}$ are sufficient to activate inhibitory $\mathrm{D}_{2}$ autoreceptors fully or that DA release and metabolism in the striatum is not tightly controlled by impulse-regulating DA autoreceptors in the SNR. In support of the latter possibility, Westerink (1979) has found that, while haloperidol $(0.5 \mathrm{mg} / \mathrm{kg}$, s.c.) increases 3-methoxytyramine (3-MT) concentrations in striatal tissue, it fails to alter nigral 3-MT concentrations. The inability of apomorphine or haloperidol to influence the rate of disappearance of DA in the $\mathrm{SN}$ after $\alpha$-methylparatyrosine also suggests that DA release and metabolism in the SN is not regulated by local DA receptors (Nissbrandt et al., 1985). Microdialysis studies in which the SNR is perfused with $D_{2}$ receptor agonists and antagonists will be required to assess further the degree to which DA autoreceptors in the SN regulate DA release in the striatum and SN.

Although elevation of DA concentrations in the SNR by nomifensine $(10 \mu \mathrm{M})$ did not alter extracellular DA or metabolites in the striatum, depolarization of the SNR with high $\mathrm{KCl}(50$ $\mathrm{mM}$ ) decreased striatal DA by approximately $20 \%$, while DOPAC and HVA were elevated. Because $\mathrm{KCl}(50 \mathrm{~mm}$ ) elevated DA output in the SNR 3.5-fold while nomifensine increased DA output by sevenfold, it seems unlikely that enhanced dendritic release of DA and its subsequent effects on DA autoreceptors could have been responsible for the potassium-induced reduction in striatal DA output. Alternatively, perfusion of the SNR with a high concentration of $\mathrm{KCl}$ may have decreased the activity of nigrostriatal neurons by interfering with their generation of action potentials. Because a neuron must repolarize bcforc a subsequent action potential can be generated, and because repolarization is mediated by an outward movement of potassium ions through voltage-sensitive channels (Hille, 1984), an increase in the extracellular concentration of potassium in the SNR would oppose this outward flux, thus preventing repolarization and the generation of action potentials. The elevated metabolites in the striatal dialysate after nigral perfusion with high potassium may have been due to an increase in the availability of intraneuronal DA for conversion to DOPAC and HVA. Similarly, perfusion of the SNR with high potassium may have decreased the DA metabolite output in the $\mathrm{SN}$ by reducing the availability of intraneuronal DA for conversion to DOPAC and HVA.

$d$-amphetamine $(2 \mathrm{mg} / \mathrm{kg}$, s.c.) produced a five- to sevenfold increase in DA release in the striatum and SNR. The time courses of this effect were identical in the two structures, suggesting that amphetamine has similar actions on DA release in the striatum and SNR. Systemic administration of amphetamine has also been shown to increase the release of endogenous DA from the A10 region (Kalivas et al., 1989). In addition, amphetamine has been shown to increase the release of newly synthesized ${ }^{3} \mathrm{H}-\mathrm{DA}$ from nigral slices (Paden et al., 1976) and from the SN after local administration (Cheramy et al., 1978). The ability of intranigral injections of $D_{1}$ receptor antagonists to attenuate the locomotor stimulant and sensitizing effects of amphetamine suggests that dendritic release of DA plays a significant role in regulating basal ganglia output (Jackson and
Kelly, 1983; Stewart and Vezina, 1989). However, systemic administration of amphetamine fails to alter the excitability of $D_{1}$ receptor-bearing striatonigral terminals in the SNR (Ryan et al., 1989). Consequently, it is unclear whether $D_{1}$ receptors on the terminals of striatonigral neurons are influenced by amphetamine administration. Nevertheless, the present data provide direct evidence that $d$-amphetamine can indeed increase DA release in the SNR of awake, freely moving animals.

The present study also indicates that dendritic release of DA in the SNR shares many of the characteristics of striatal DA release. Nevertheless, there are some differences in DA metabolism in the two structures. For example, while peripheral administration of $d$-amphetamine decreased DOPAC and HVA concentrations in the striatum, only DOPAC was significantly reduced in the SNR. A dissociation between DOPAC and HVA metabolism was also seen in the SNR after nigral application of TTX $(1 \mu \mathrm{M})$. TTX only increased the extracellular concentrations of HVA in the SNR, while both DOPAC and HVA were elevated in the striatal dialysate by this treatment. One interpretation of these results is that nigral HVA is derived largely from 3-MT, while striatal HVA is derived to a greater extent from DOPAC. The finding that monoamine oxidase inhibition produces a greater accumulation of 3-MT in the SN than in the striatum is consistent with the possibility that O-methylation may be a more important metabolic route in the SN (Nissbrandt et al., 1985). The prominence of O-methylation in the $\mathrm{SN}$ is also indicated by the 3-MT:DA ratio after monoamine oxidase inhibition, this being 0.1 in striatum and 0.5 in SN (Nissbrandt et al., 1985).

In summary, the results of the present study demonstrate that dendritic release of DA in the SNR shares many of the properties associated with DA release in the striatum. Nigral DA release was increased by high potassium, nomifensine, and $d$-amphetamine and blocked by TTX. The similarities in nigral and striatal DA release suggest that dendritic DA release serves a complementary role to that of terminal DA release in the striatum. Dopaminergic dendrites are strategically positioned to modulate the activity of striatonigral terminals in the SNR. Hence, by activating $D_{1}$ receptors located on the terminals of striatonigral neurons, dendritically released DA may modulate striatal outflow and thereby play an important role in basal ganglia function (Robertson and Robertson, 1987).

\section{References}

Aghajanian GK, Bunney BS (1977) Dopamine's autoreceptors: pharmacological characterization by microiontophoretic single cell recording studies. Naunyn-Schmiedebergs Arch Pharmacol 197:1-7.

Anden N-E, Rubenson A, Fuxe K, Hökfelt T (1967) Evidence for dopamine receptor stimulation by apomorphine. J Pharm Pharmacol 19:627-629.

Anden N-E, Corrodi H, Fuxe K, Ungerstedt U (1971) Importance of nervous impulse flow for the neuroleptic induced increase in amine turnover in central dopamine neurons. Eur J Pharmacol 15:193-199.

Björklund A, Lindvall O (1975) Dopamine in dendrites of the substantia nigra neurons: suggestions for a role in dendritic terminals. Brain Res 83:531-537.

Cheramy A, Nieoullon A, Glowinski J (1978) In vivo changes in dopamine release in cat caudate nucleus and substantia nigra induced by nigral application of various drugs including GABAergic agonists and antagonists. In: Interactions between putative neurotransmitters in the brain (Garattini S, Pujol JF, Samanin R, eds), pp 175-190. New York: Raven.

Cheramy A, Leviel V, Glowinski J (1981) Dendritic release of dopamine in the substantia nigra. Nature 289:537-542.

Church WH, Justice JB Jr (1987) Rapid sampling and determination of extracellular dopamine in vivo. Anal Chem 59:712-716. 
Damsma G, Boisvert DP, Mudrick LA, Wenkstern D, Fibiger HC (1990) Effects of transient forebrain ischemia and pargyline on extracellular concentrations of dopamine, serotonin, and their metabolites in the striatum as determined by in vivo microdialysis. J Neurochem 54 : 801-808.

Dray A, Gonye TJ, Oakley NR, Tanner T (1976) Evidence for the existence of a raphe projection to the substantia nigra in the rat. Brain Res 113:45-57.

Fibiger HC, Miller JJ (1977) An anatomical and electrophysiological investigation of the serotonergic projection from the dorsal raphe nucleus to the substantia nigra of the rat. Neuroscience 2:975-987.

Gale K, Guidotti A, Costa E (1977) Dopamine-sensitive adenylate cyclase: location in the substantia nigra. Science 195:503-505.

Gauchy C, Kemel ML, Romo R, Glowinski J, Besson MJ (1987) The role of dopamine released from distal and proximal dendrites of nigrostriatal dopaminergic neurons in the control of GABA transmission in the thalamic nucleus ventralis medialis in the cat. Neuroscience 22:935-946.

Geffen LB, Jessell TM, Cuello AC, Iversen LL (1976) Release of dopamine from dendrites in rat substantia nigra. Nature 260:258-260.

Groves PM, Wilson CJ, Young SJ, Rebec GV (1975) Self-inhibition by dopaminergic neurons. Science 190:522-529.

Hille B (1984) Ionic channels of excitable membranes. Sunderland, MA: Sinauer.

Hökfelt T, Martensson R, Björklund A, Kleinau S, Goldstein M (1984) Distributional maps of tyrosine-hydroxylase-immunoreactive neurons in the rat brain. In: Handbook of chemical neuroanatomy, Vol 2, Classical transmitters in the CNS, Pt 1 (Björklund A, Hökfelt T, eds), pp 277-397. New York: Elsevier.

Jackson EA, Kelly PH (1983) Role of nigral dopamine in amphetamine-induced locomotor activity. Brain Res 278:366-369.

Jackson EA, Kelly PH (1984) Nigral dopaminergic mechanisms in drug-induced circling. Brain Res Bull 11:605-611.

Jaeger CB, Ruggiero DA, Albert VR, Joh TH, Reis DJ (1984) Immunocytochemical localization of aromatic-L-aminoacid decarboxylase. In: Handbook of chemical neuroanatomy, Vol 2, Classical transmitters in the CNS, Pt 1 (Björklund A, Hökfelt T, eds), pp 387406. New York: Elsevier.

Kalivas PW, Bourdelais A, Abhold R, Abbott L (1989) Somatodendritic release of endogenous dopamine: in vivo dialysis in the A10 dopamine region. Neurosci Lett 100:215-220.

Kelly E, Jenner P, Marsden CD (1984) Behavioural effects mediated by unilateral nigral dopamine stimulation in the rat. Exp Brain Res 55:243-252.

Kelly E, Jenner P, Marsden CD (1985) Evidence that $\left[{ }^{3} \mathrm{H}-\right.$ DA]dopamine is taken up and released from nondopaminergic nerve terminals in the rat substantia nigra in vitro. J Neurochem 45:137144.

Kozlowski MR, Sawyer S, Marshall JF (1980) Behavioural effects and supersensitivity following nigral dopamine receptor stimulation. $\mathrm{Na}-$ ture 287:52-54.

Nedergaard S, Webb C, Greenfield SA (1989) A possible ionic basis for dendritic release of dopamine in the guinea-pig substantia nigra. Acta Physiol Scand 135:67-68.
Nieoullon A, Cheramy A, Glowinski J (1977a) Release of dopamine in vivo from cat substant $\rightarrow$ nigra. Nature $266: 375-377$.

Nieoullon A, Cheramy A, Glowinski J (1977b) Interdependence of the nigrostriatal dopaminergic systems on the two sides of the brain of the cat. Science 198:416-418.

Nissbrandt H, Pileblad E, Carlson A (1985) Evidence for dopamine release and metabolism beyond the control of nerve impulses and dopamine receptors in the rat substantia nigra. J Pharm Pharmacol 37:884-889.

Nomikos GG, Damsma G, Wenkstern D, Fibiger HC (1990) In vivo characterization of locally applied dopamine uptake inhibitors by striatal microdialysis. Synapse 6:106-112.

Paden C, Wilson CJ, Groves PM (1976) Amphetamine-induced release of dopamine from the substantia nigra in vitro. Life Sci 19:14991506.

Paxinos G, Watson C (1986) The rat brain in stereotaxic coordinates, 2nd ed. New York: Academic.

Reisine JC, Nagy JI, Fibiger HC, Yamamura HI (1979) Localization of dopamine receptors in rat brain. Brain Res 169:209-214.

Reubi J-C, Iversen LL, Jessell TM (1977) Dopamine selectively increases ${ }^{3} \mathrm{H}-\mathrm{GABA}$ release from slices of rat substantia nigra in vitro. Nature 268:652-654.

Robertson GS, Robertson HA (1987) $D_{1}$ and $D_{2}$ dopamine agonist synergism: separate sites of action? Trends Pharmacol Sci 8:295-299.

Robertson GS, Robertson HA (1989) Evidence that L-dopa-induced rotational behavior is dependent on both striatal and nigral mechanisms. J Neurosci 9:3326-3331.

Robinson TE, Whishaw IQ (1988) Normalization of extracellular dopamine in striatum following recovery from a partial unilateral 6-OHDA lesion of the substantia nigra: a microdialysis study in freely moving rats. Brain Res 450:209-224.

Ryan LJ, Diana M, Young SJ, Groves PM (1989) Dopamine D1 heteroreceptors on striatonigral axons are not stimulated by endogenous dopamine either tonically or after amphetamine: evidence from terminal excitability. Exp Brain Res 77:161-165.

Starr MS (1987) Opposing roles of D-1 and D-2 receptors in nigral $\gamma-\left({ }^{3} \mathrm{H}\right)$ aminobutyric acid release? J Neurochem 49:1042-1049.

Starr MS, Starr BS (1989) Circling evoked by intranigral SKF 38393 a GABA-mediated D-1 response? Pharmcol Biochem Behav 32:849851

Stewart J, Vezina P (1989) Microinjections of SCH-23390 into the ventral tegmental area and substantia nigra pars reticulata attenuate the development of sensitization to the locomotor activating effects of systemic amphetamine. Brain Res 495:401-406.

Westerink BHC (1979) Effect of drugs on the formation of 3-methoxytyramine, a dopamine metabolite, in the substantia nigra, striatum, nucleus accumbens and tuberculum olfactorium of the rat. J Pharm Pharmacol 31:94-99.

Westerink BHC, De Vries JB (1988) Characterization of in vivo dopamine release as determined by brain microdialysis after acute and subchronic implantations: methodological aspects. J Neurochem 51: 683-687. 